\title{
FAKTOR PENENTU FINANCIAL DISTRESS PERUSAHAAN RESTORAN, HOTEL, DAN PARIWISATA YANG TERDAFTAR DI BURSA EFEK INDONESIA
}

\author{
Calvin Agusty Nason', Yusbardini² \\ ${ }^{1}$ Program Studi Manajemen Fakultas Ekonomi dan Bisnis, Universitas Tarumanagara, Jakarta \\ Email: calvin.115180272@stu.untar.ac.id \\ ${ }^{2}$ Program Studi Manajemen Fakultas Ekonomi dan Bisnis, Universitas Tarumanagara, Jakarta \\ Email: yusbardini@fe.untar.ac.id
}

Masuk : 15-01-2022, revisi: 20-01-2022, diterima untuk diterbitkan : 25-01-2022

\begin{abstract}
ABSTRAK
Tujuan penelitian ini adalah untuk mengetahui faktor - faktor apa saja yang dapat menentukan atau mempengaruhi financial distress pada suatu perusahaan. Subjek pada penelitian ini adalah perusahaan restoran, hotel, dan pariwisata yang terdaftar di Bursa Efek Indonesia periode 2018-2020. Penelitian ini menggunakan data sekunder berupa laporan keuangan tahunan perusahaan yang diambil dari situs resmi Bursa Efek Indonesia dan situs perusahaan masing - masing. Metode pemilihan sampel yang digunakan dalam penelitian ini berupa purposive sampling dengan kriteria yang dibutuhkan peneliti dalam penelitian ini. Penelitian ini mengumpulkan data sebanyak 28 perusahaan dari 46 perusahaan restoran, hotel, dan pariwisata, dengan jumlah observasi sebesar 84 sampel. Pengolahan data pada penelitian ini menggunakan program Microsoft Excel 10. Penelitian ini menggunakan teknik analisis regresi logistik yang dilakukan dengan menggunakan program Eviews 10. Hasil penelitian ini menunjukkan bahwa long term debt to equity ratio mempunyai pengaruh positif dan signifikan terhadap financial distress. Di sisi lain, variabel return on investment memiliki pengaruh negatif dan signifikan terhadap financial distress. Sedangkan pada variabel retention ratio, managerial ownership, dan institutional ownership ditemukan tidak memiliki pengaruh signifikan terhadap financial distress.
\end{abstract}

Kata Kunci: Financial Distress, Variabel Keuangan, Variabel non Keuangan

\begin{abstract}
The purpose of this study is to determine what factors can determine or affect financial distress in a company. The subjects of this research are restaurant, hotel, and tourism companies listed on the Indonesia Stock Exchange for the period 2018-2020. This study uses secondary data in the form of the company's annual financial statements taken from the official website of the Indonesia Stock Exchange and the websites of their respective companies. The sample selection method used in this study was purposive sampling with the criteria needed by researchers in this study. This study collected data from 28 companies from 46 restaurant, hotel, and tourism companies, with a total of 84 samples of observations. Processing data in this study using Microsoft Excel 10 program. This study uses logistic regression analysis techniques performed using the Eviews 10 program. The results of this study indicate that the long term debt to equity ratio has a positive and significant effect on financial distress. On the other hand, the return on investment variable has a negative and significant effect on financial distress. Meanwhile, the retention ratio, managerial ownership, and institutional ownership variables were found to have no significant effect on financial distress.
\end{abstract}

Keywords: Financial Distress, Financial Variables, Non-Financial Variables

\section{PENDAHULUAN}

\section{Latar Belakang}

Pada awal Maret 2020, masuknya pandemi Covid-19 (Coronavirus Disease 2019) ke Indonesia telah menyebabkan perubahan yang signifikan terhadap seluruh tatanan kehidupan di Indonesia, terutama pada sektor pereknonomian. Berdasarkan data kemenparekraf (2019), kontribusi sektor pariwisata terhadap PDB (Pendapatan Domestik Bruto) nasional pada tahun 2020 mengalami penurunan dari 5,5\% menjadi hanya 4\%, yang dimana merupakan kontribusi terendah semenjak tahun 2013. Wakil ketua Perhimpunan Hotel dan Restoran Indonesia (PHRI) Maulana Yusran, 
mengatakan bahwa saat ini industri pariwisata, hotel, dan restoran menderita kerugian mencapai lebih dari Rp 100 triliun atau US\$ 7,1 miliar hingga awal November (Kontan.co.id, 2020). Berdasarkan pernyataan tersebut, maka dapat dikatakan bahwa banyak perusahaan sektor restoran, hotel, dan pariwisata mengalami kondisi kesulitan keuangan atau yang disebut financial distress.

Menurut Platt dan Platt (2002), financial distress adalah tahap akhir penurunan kondisi keuangan perusahaan. Yusbardini dan Rashid (2019) menyatakan bahwa financial distress merupakan suatu kondisi dimana perusahaan mengalami kesulitan keuangan untuk memenuhi kewajiban - kewajibannya. Dengan kata lain, jika kondisi financial distress terus berlanjut, maka perusahaan akan menghadapi likuidasi atau kebangkrutan. Kebangkrutan tentunya akan merugikan banyak pihak, pada penelitian Al-Khatib dan Al-Horani (2012) dinyatakan bahwa kebangkrutan perusahaan akan menimbulkan kerugian bagi para pemilik saham, karyawan, dan perekonomian nasional. Oleh karena itu, prediksi financial distress harus dilakukan sejak awal agar kondisi kebangkrutan dapat dihindar. Hal tersebut didukung oleh penelitian Kristian (2017) yang menyatakan bahwa prediksi financial distress harus dilakukan sejak dini agar manajemen dapat mengetahui efektivitas kebijakan yang tepat jika perusahaan mengarah ke financial distress.

Terdapat banyak faktor yang dapat mempengaruhi financial distress suatu perusahaan seperti return on equity, interest coverage ratio, net profit margin, net asset value, long term debt to equity ratio, return on investment, retention ratio, age, promoters holdings pledged, institutional holdings, ownership concentration, managerial ownership dan outside shareholders. Dalam penelitian ini, peneliti hanya memilih pengaruh tiga variabel keuangan (long term debt to equity ratio, retention ratio, \& return on investment) dan dua variabel non-keuangan (managerial ownership \& institutional ownership) terhadap financial distress perusahaan.

\section{Kajian Teori \\ Trade Off Theory}

Trade off theory adalah studi yang menjelaskan tentang penggunaan struktur modal yang optimal dengan menyeimbangkan keuntungan atas penggunaaan hutang (leverage). Pada penelitian Myers (2001, dalam Umdiana \& Claudia, 2020) dinyatakan bahwa “. . . perusahaan akan berutang sampai pada tingkat utang tertentu, dimana penghematan pajak (tax shields) dari tambahan utang sama dengan biaya kesulitan keuangan (financial stress)." Dari pernyataan tersebut dapat diartikan bahwa penambahan utang yang berlebihan akan menambahkan risiko perusahaan mengalami financial distress.

\section{Signalling Theory}

Signalling theory pertama kali diperkenalkan oleh Michael Spence pada tahun 1973 yang meneliti hubungan antara organisasi/perusahaan dengan calon karyawan. Menurut Connelly, Certo, Ireland, dan Reutzel (2011), proses dari signalling theory adalah pihak yang mempunyai informasi memberikan sinyal kepada pihak penerima, kemudian pihak penerima akan menilai sinyal tersebut dan memberikan masukan kepada pihak yang mempunyai informasi. Variabel financial distress dapat dikaitkan dengan signalling theory. Keterkaitan ini terletak pada cara pihak perusahaan atau manajer menyampaikan informasi kepada pemilik saham jika terjadi financial distress atau sebaliknya. Berdasarkan informasi yang diterima, maka pemilik saham dapat membuat keputusan atau melakukan pengawasan terhadap aktivitas manajemen perusahaan sehingga terhindar dari kondisi financial distress. 


\section{Agency Theory}

Menurut Jensen dan Meckling (1976), agency theory adalah teori yang muncul karena adanya agency relationship antara principals (pemegang saham) dan agent (manajemen). Adanya hubungan antara principals dan agent dapat memunculkan suatu konflik, dan jika konflik antara principals dan agent terus berlanjut, maka perusahaan dapat mengalami financial distress.

\section{Financial Distress}

Menurut Platt dan Platt (2002), "Financial distress is defined as a late stage of corporate decline that precedes more cataclysmis events such as bankruptcy or liquidation." Financial distress adalah kondisi disaat perusahaan mengalami penurunan secara finansial dan tidak dapat membayar kewajibannya, yang dapat mengakibatkan perusahaan mengalami kebangkrutan atau likuidasi.

\section{Long Term Debt to Equity Ratio}

Menurut Kasmir (2009, h. 114), "Long Term Debt to Equity Ratio merupakan rasio antara utang jangka panjang dengan modal sendiri." Menurutnya, tujuan long term debt to equity ratio adalah untuk mengukur berapa bagian dari setiap rupiah modal sendiri yang dijadikan jaminan utang jangka panjang dengan cara membandingkan antara utang jangka panjang dengan modal sendiri yang disediakan oleh perusahaan. Sehingga disimpulkan bahwa Long term debt to equity ratio adalah rasio yang mengukur utang jangka panjang dengan modal perusahaan itu sendiri. Berdasarkan trade off theory, dinyatakan bahwa penggunaan utang yang berlebihan akan meningkatkan kemungkinan perusahaan mengalami financial distress. Artinya jika long term debt to equity ratio perusahaan semakin meningkat, maka kemungkinan perusahaan mengalami financial distress juga akan meningkat.

\section{Retention Ratio}

Murphy (2021) menjelaskan bahwa "The retention ratio is the proportion of earnings kept back in the business as retained earnings. The retention ratio refers to percentage of net income that is retained to grow the business, rather than being paid out as dividends." Berdasarkan penjelasan tersebut, maka retention ratio dapat didefinisikan sebagai rasio profitabilitas yang mengukur proporsi pendapatan perusahaan yang disimpan kembali guna untuk operasional perusahaan kedepannya. Berdasar pada trade off theory, pendanaan perusahaan yang menggunakan utang berlebihan akan membawa perusahaan ke dalam kondisi financial distress, sebaliknya jika pendanaan perusahaan menggunakan modal perusahaan itu sendiri, maka perusahaan tidak perlu membayar hutang. Dengan kata lain, semakin tingginya nilai retention ratio, maka akan semakin rendah kemungkinan terjadinya financial distress.

\section{Return on Investment}

Kasmir (2009, h. 117) menjelaskan bahwa "Return on Investment (ROI) atau Return on Total Assets, merupakan rasio yang menunjukkan hasil (return) atas jumlah aktiva yang digunakan dalam perusahaan. ROI juga merupakan suatu ukuran tentang efektivitas manajemen dalam mengelola investasinya." Return on investment merupakan rasio yang menunjukkan hasil atas investasi yang dilakukan oleh perusahaan. Pada agency theory dijelaskan adanya konflik kepentingan antara principals dan agent karena adanya asimetri informasi. Return on investment merupakan tanggung jawab agent terhadap principals. Jika nilai return on investment perusahaan tinggi, maka tentunya tidak akan terjadi konflik antara kedua pihak. Tetapi jika nilai return on investment rendah, maka akan terjadi konflik keagenan tersebut. Sehingga semakin tingginya nilai return on investment, maka akan semakin rendah kemungkinan perusahaan mengalami financial distress. 


\section{Managerial Ownership}

Witiastuti dan Suryandari (2016) menjelaskan bahwa "Managerial Ownership is the ammount of the company shares which are owned by the management of the firm's manager, the form of ownership by the Board of Directors and Board of Commissioners." Artinya, Managerial ownership adalah proporsi saham yang dimiliki oleh para manajemen perusahaan seperti dewan direksi dan dewan komisaris. Berdasarkan agency theory, konflik keagenan muncul karena adanya konflik kepentingan antara principals dengan agent. Jensen dan Meckling (1973) menyatakan bahwa agent tidak selalu bertindak sesuai dengan sudut pandang principals. Tetapi jika agent memiliki saham di perusahaan, maka agent akan bertindak sesuai dengan sudut pandang principals. Karena jika perusahaan mengalami keuntungan, agent juga akan mendapatkan hasilnya. Dengan kata lain, semakin besar jumlah managerial ownership akan semakin mengurangi kemungkinan terjadinya financial distress pada perusahaan.

\section{Institutional Ownership.}

Penelitian Chung dan Zhang (2009) menyatakan "We define institutional ownership as the fraction of a firm's shares that are held by institutional investors." Instituional investors yang dimaksud adalah bank, perusahaan asuransi, dan dana pensiun yang memiliki fiduciary responbilities yang kuat. Dengan kata lain, institutional ownership merupakan proposi saham perusahaan yang dimiliki oleh institusi berupa lembaga keuangan, perusahaan asuransi, dana pensiun, dan lainnya dari total jumlah saham yang beredar. Berdasarkan signalling theory, perusahaan akan memberi sinyal kepada pemilik saham akan informasi yang dimilikinya seperti laporan keuangan, kemudian pemilik saham akan memberikan respon terhadap sinyal tersebut berupa pengawasan terhadap aktivitas manajemen perusahaan. Witiastuti dan Suryandari (2016) juga menyatakan bahwa dalam perspektif agency theory, keberadaan institutional ownership akan meningkatkan kinerja perusahaan, karena institutional ownership akan selalu mengawasi kinerja dari perusahaan. Oleh karena itu, dapat dinyatakan bahwa semakin besarnya jumlah institutional ownership akan mengurangi kemungkinan perusahaan mengalami financial distress. Berdasarkan kajian teori yang telah dipaparkan, maka disajikan kerangka pemikiran dan hipotesis sebagai berikut:

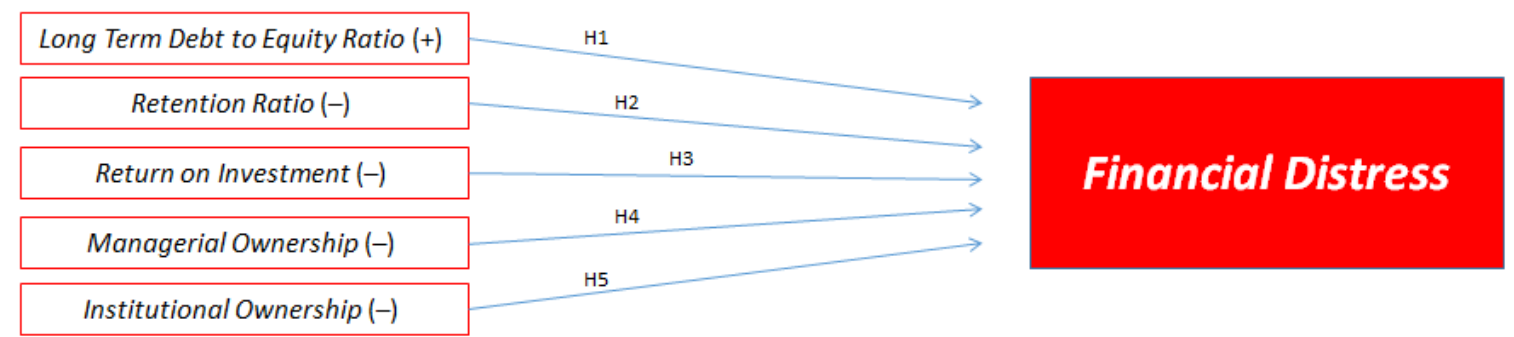

\section{Gambar 1. Kerangka pemikiran}

H1: Long term debt to equity ratio berpengaruh positif dan signifikan terhadap financial distress.

$\mathrm{H} 2$ : Retention ratio berpengaruh negatif dan signifikan terhadap financial distress.

H3: Return on investment berpengaruh negatif dan signifikan terhadap financial distress.

H4: Managerial ownership berpengaruh negatif dan signifikan terhadap financial distress.

H5: Institutional ownership berpengaruh negatif dan signifikan terhadap financial distress.

\section{METODE PENELITIAN}

Desain penelitian ini menggunakan desain penelitian deskriptif dengan pendekatan kuantitatif. Penelitian ini menggunakan data sekunder berupa laporan keuangan perusahaan sektor restoran, hotel, dan pariwisata yang terdaftar di Bursa Efek Indonesia pada periode 2018-2020. Data 
diperoleh melalui situs resmi Bursa Efek Indonesia yaitu: www.idx.co.id dan juga situs perusahaan masing - masing. Metode pemilihan sampel pada penelitian ini menggunakan metode tidak acak, yaitu dengan teknik purposive sampling dengan kriteria yaitu: 1) Perusahaan restoran, hotel, dan pariwisata yang terdaftar dan tercatat dalam data pasar Bursa Efek Indonesia. 2) Perusahaan restoran, hotel, dan pariwisata yang terdaftar minimal sejak tahun 2018 dan masih beroperasi hingga 2020 berturut-turut. 3) Perusahaan restoran, hotel, dan pariwisata yang terdaftar memiliki laporan keuangan yang telah diaudit selama periode 2018-2020. 4) Perusahaan restoran, hotel, dan pariwisata yang menyajikan laporan keuangan dalam satuan mata uang Rupiah.

Tabel 1. Operasionalisasi Variabel

\begin{tabular}{|c|c|c|}
\hline Variabel & Ukuran & Skala \\
\hline Financial Distress & $6,56 \frac{W C}{T A}+3.26 \frac{R E}{T A}+6,72 \frac{E B I T}{T A}+1,05 \frac{B V E q u i t y}{B V \text { Debt }}$ & Nominal \\
\hline $\begin{array}{c}\text { Long Term Debt to } \\
\text { Equity Ratio }\end{array}$ & $\frac{\text { Long Term Debt }}{\text { Total Equity }}$ & Rasio \\
\hline Retention Ratio & $\frac{\text { (Net Income }- \text { Dividens) }}{\text { Net lncome }}$ & Rasio \\
\hline Return On Investment & $\frac{\text { Net Income }}{\text { Total Investment }}$ & Rasio \\
\hline Managerial Ownership & $\frac{\text { lumlah Kepemilikan Saham oleh Manajemen }}{\text { Jumlah Saham yang Beredar }}$ & Rasio \\
\hline Institutional Ownership & $\frac{\text { Jumlah Kepemilikan Saham oleh Institusi }}{\text { Jumlah Saham yang Beredar }}$ & Rasio \\
\hline
\end{tabular}

Pengujian yang dilakukan dalam penelitian ini terdiri atas uji statistik deskriptif, uji analisis regresi logistik, uji koefisien determinansi (McFadden $R$-Squarred), uji likelihood ratio, uji kelayakan model (Hosmer and Lemeshow Goodness of Fit Test), dan uji statistik Z dengan menggunakan program Eviews 10.

\section{HASIL DAN PEMBAHASAN Statistik Deskriptif}

Variabel financial distress memiliki nilai maksimum 1,000000 dan nilai minimum 0,000000. Nilai maksimum 1,000000 menggambarkan perusahaan mengalami financial distress, sedangkan nilai minimum 0,000000 menggambarkan perusahaan tidak mengalami financial distress. Nilai rata - rata dan standar deviasi financial distress berturut-turut sebesar 0,357143 dan 0,482035. Variabel long term debt to equity ratio memiliki nilai maksimum sebesar 3,780540 dan nilai minimum sebesar 0,000000. Nilai rata - rata dan standar deviasi long term debt to equity ratio berturut - turut sebesar 0,512693 dan 0,714346 . Variabel retention ratio memiliki nilai maksimum sebesar 1,000000 dan nilai minimum sebesar $-13,18547$. Nilai rata - rata dan standar deviasi retention ratio berturut - turut sebesar 0,726559 dan 1,553406 . Variabel return on investment memiliki nilai maksimum sebesar 0,260471 dan nilai minimum sebesar -0,257469. Nilai rata - rata dan standar deviasi return on investment berturut - turut sebesar -0,004795 dan 0,068345 . Variabel managerial ownership memiliki nilai maksimum sebesar 0,742857 dan nilai minimum sebesar 0,000000. Nilai rata - rata dan standar deviasi managerial ownership berturut - turut sebesar 0,049160 dan 0,133583. Variabel institutional ownership memiliki nilai 
maksimum sebesar 0,977600 dan nilai minimum sebesar 0,000000. Nilai rata - rata dan standar deviasi institutional ownership berturut - turut sebesar 0,179571 dan 0,267869.

\section{Analisis Regresi Logistik}

Hasil pengujian model regresi logistik adalah sebagai berikut:

Tabel 2. Hasil Uji Analisis Regresi Logistik

Sumber: Hasil output Eviews 10

Dependent Variable: FD

Method: ML - Binary Logit (Newton-Raphson / Marquardt steps)

Date: 11/24/21 Time: 15:09

Sample (adjusted): 184

Included observations: 84 after adjustments

Convergence achieved after 8 iterations

Coefficient covariance computed using observed Hessian

\begin{tabular}{crlrr}
\hline \hline \multicolumn{1}{c}{ Variable } & Coefficient & Std. Error & z-Statistic & Prob. \\
\hline \hline C & $-4,257750$ & 1,257779 & $-3,385134$ & 0,0007 \\
RTDE & 8,025862 & 2,283861 & 3,514164 & 0,0004 \\
ROI & 0,077985 & 0,689644 & 0,113080 & 0,9100 \\
MO & $-24,27136$ & 7,923942 & $-3,063041$ & 0,0022 \\
IO & 1,020466 & 2,575411 & 0,396234 & 0,6919 \\
& $-0,018107$ & 1,317883 & $-0,013739$ & 0,9890 \\
\hline \hline McFadden R-squared & 0,556871 & Mean dependent var & 0,357143 \\
S.D. dependent var & 0,482035 & S.E. of regression & 0,313581 \\
Akaike info criterion & 0,720482 & Sum squared resid & 7,669958 \\
Schwarz criterion & 0,894112 & Log likelihood & $-24,26024$ \\
Hannan-Quinn criter. & 0,790280 & Deviance & 48,52047 \\
Restr. deviance & 109,4951 & Restr. log likelihood & $-54,74755$ \\
LR statistic & 60,97463 & Avg. log likelihood & $-0,288812$ \\
Prob(LR statistic) & 0,000000 & & & \\
\hline \hline & & & & \\
Obs with Dep=0 & \multirow{2}{*}{54} & Total obs & \\
Obs with Dep=1 & 30 & & \\
\hline \hline
\end{tabular}

Berdasarkan Tabel 2 di atas, maka dapat dirumuskan model persamaan regresi logistik sebagai berikut:

$$
\begin{aligned}
\operatorname{Ln}\left(\frac{P}{1-p}\right)= & -4.257750+8.025862 L T D E R+0.077985 R R-24.27136 R O I \\
& +1.020466 M O-0.018107 I O
\end{aligned}
$$

\section{Uji Koefisien Determinansi (McFadden R-Squarred)}

Berdasarkan hasil uji pada Tabel 2, dapat diketahui bahwa nilai McFadden R-Squared adalah sebesar 0,556871. Angka tersebut mencerminkan bahwa variabel long term debt to equity ratio, retention ratio, return on investment, managerial ownership, dan institutional ownership dapat menjelaskan variabel financial distress sebesar 55,6871\%, sedangkan sisanya sebesar 44,3129\% dijelaskan oleh faktor - faktor lain di luar penelitian ini. 


\section{Uji Likelihood Ratio}

Berdasarkan hasil uji Tabel 2, dapat terlihat bahwa nilai probabilitas (LR statistic) adalah sebesar $0,000000<$ tingkat signifikan $5 \%$. Hal ini menunjukkan bahwa $\mathrm{H}_{0}$ ditolak dan $\mathrm{H}_{\mathrm{a}}$ diterima, artinya long term debt to equity ratio, retention ratio, return on investment, managerial ownership, dan institutional ownership, secara bersama-sama memiliki pengaruh signifikan terhadap financial distress.

\section{Uji Kelayakan Model (Hosmer and Lemeshow Goodness of Fit Test)}

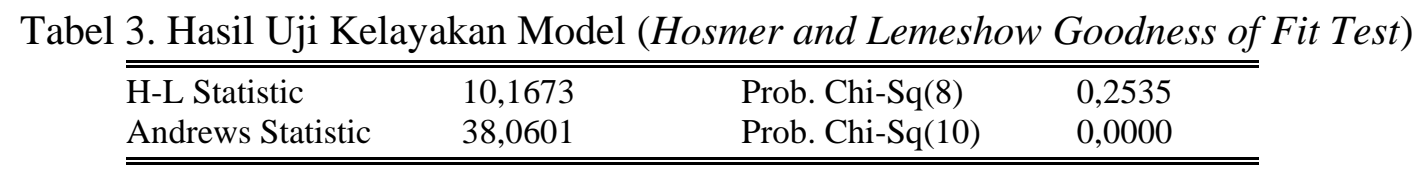

Berdasarkan hasil uji Tabel 3, dapat diketahui bahwa hasil probabilitas Hosmer and Lemeshow Goodness of Fit Test adalah sebesar 0,2535 > tingkat signifikan 5\%, maka $\mathrm{H}_{0}$ ditolak dan $\mathrm{H}_{\mathrm{a}}$ diterima. Artinya, model regresi yang dihipotesiskan cocok dengan data penelitian.

\section{Uji Statistik Z}

Berdasarkan hasil uji Tabel 2, dapat terlihat bahwa variabel long term debt to equity ratio dan return on investment memiliki nilai probabilitas sebesar 0,0004 dan 0,0022 yang lebih kecil dari taraf signifikansi 0,05. Sehingga dapat disimpulkan bahwa $\mathrm{H} 1$ dan $\mathrm{H} 3$ tidak ditolak, yang berarti variabel long term debt to equity ratio dan return on investment memiliki pengaruh signifikan terhadap financial distress dengan tingkat kepercayaan $95 \%$. Variabel retention ratio, managerial ownership, dan institutional ownership berturut-turut memiliki nilai probabilitas sebesar 0,9100, 0,6919, dan 0,9890 yang lebih besar dari taraf signifikansi 0,05. Sehingga dapat disimpulkan bahwa $\mathrm{H} 2, \mathrm{H} 4$, dan $\mathrm{H} 5$ ditolak, artinya variabel retention ratio, managerial ownership, dan institutional ownership tidak memiliki pengaruh signifikan terhadap financial distress perusahaan dengan tingkat keyakinan $95 \%$.

\section{Pembahasan}

Variabel long term debt to equity ratio memiliki pengaruh positif dan signifikan terhadap variabel financial distress. Hasil penelitian ini sejalan dengan hasil penelitian yang dilakukan oleh Platt dan Platt (2002) dan Balasubramanian dkk. (2019) yang menyatakan bahwa adanya pengaruh positif dan signifikan antara variabel long term debt to equity ratio terhadap variabel financial distress. Penelitian ini menolak hasil penelitian Sanchiani dan Bernawati (2018) yang menemukan hasil bahwa long term debt to equity ratio berpengaruh negatif dan signifikan terhadap financial distress. Hasil kontradiktif juga ditemukan dalam penelitian Al-Khatib dan Al-Horani (2012) dan Ratna dan Marwati (2018), penelitian tersebut menemukan hasil tidak adanya pengaruh signifikan antara variabel long term debt to equity ratio terhadap financial distress perusahaan. Hasil penelitian ini mencerminkan bahwa semakin tinggi hutang jangka panjang yang dimiliki oleh perusahaan, maka akan semakin tinggi juga kemungkinan untuk mengalami financial distress.

Variabel retention ratio tidak berpengaruh signifikan terhadap variabel financial distress. Hasil penelitian ini tidak sejalan dengan penelitian yang dilakukan oleh Balasubramanian dkk. (2019) yang menyatakan bahwa adanya pengaruh negatif dan signifikan dari variabel retention ratio terhadap variabel financial distress. Tetapi penelitian ini sejalan dengan hasil penelitian Lieu dkk. (2008) yang menyatakan adanya pengaruh positif antara variabel retention ratio terhadap financial distress perusahaan, hanya saja hasil penelitian ini tidak memberikan hasil signifikan. 
Variabel retention ratio dihitung dengan mengurangi net income dengan dividend kemudian dibagi net income. Perusahaan dengan nilai retention ratio sebesar 1,000000 artinya perusahaan tersebut tidak melakukan pembagian dividen, sehingga nilai retention ratio-nya tinggi atau maksimum. Perusahaan tidak melakukan pembayaran dividen mungkin dikarenakan adanya tujuan ekspansi perusahaan di periode selanjutnya, sehingga pembayaran dividen ditiadakan terlebih dahulu. Tetapi pada tahun 2020, pandemi Covid-19 yang masuk ke Indonesia menyebabkan banyak perusahaan restoran, hotel, dan pariwisata mengalami kerugian, sehingga perusahaan tidak melakukan pembayaran dividen. Perusahaan tidak melakukan pembayaran dividen bukan karena untuk pendanaan operasional perusahaan pada periode selanjutnya, tetapi karena perusahaan mengalami kerugian sehingga tidak dapat melakukan pembayaran dividen kepada para pemegang saham. Maka dapat disimpulkan bahwa perusahaan dengan retention ratio yang tinggi belum tentu akan terhindar dari kemungkinan mengalami financial distress, dengan kata lain, variabel retention ratio tidak dapat menjadi faktor penentu financial distress perusahaan.

Variabel return on investment memiliki pengaruh negatif dan signifikan terhadap financial distress. Hasil penelitian ini sesuai dengan hasil penelitian yang dilakukan oleh Balasubramanian dkk. (2019), dimana ditemukan hasil bahwa variabel return on investment memiliki pengaruh negatif dan signifikan terhadap financial distress perusahaan. Sebaliknya, pada penelitian Nurhidayah dan Rizqiyah (2017) ditemukan hasil bahwa return on investment berpengaruh positif dan signifikan terhadap financial distress. Hasil yang berbeda juga ditemukan pada penelitian Platt dan Platt (2002) dan Simanjuntak dkk. (2017), ditemukan hasil bahwa tidak adanya pengaruh signifikan antara variabel return on investment terhadap financial distress perusahaan. Variabel return on investment mengukur profitabilitas dari investasi yang dilakukan perusahaan, artinya jika nilai return on investment berupa positif, menandakan bahwa perusahaan mengalami keuntungan atas investasi yang dilakukan dan begitu sebaliknya. Dengan kata lain, semakin tingginya return on investment maka akan semakin rendah kemungkinan terjadinya financial distress.

Variabel managerial ownership tidak berpengaruh signifikan terhadap variabel financial distress. Hasil penelitian ini konsisten dengan penelitian yang dilakukan oleh Li dkk. (2008) dan Witiastuti dan Suryandari (2016) yang menyatakan bahwa managerial ownership tidak berpengaruh secara signifikan terhadap financial distress perusahaan. Namun bertentangan dengan penelitian yang dilakukan oleh Hanifah dan Purwanto (2013), Emrinaldi (2007), dan Donker dkk. (2009) yang menyatakan bahwa adanya pengaruh signifikan antara variabel managerial ownership terhadap financial distress. Variabel managerial ownership memiliki nilai mean atau rata - rata sebesar 0,049160 atau hanya sebesar 4,92\%. Kecilnya jumlah managerial ownership bisa menjadi sebuah alasan mengapa managerial ownership tidak berpengaruh terhadap financial distress, karena jumlah kepemilikan yang kecil tidak mampu untuk mempengaruhi aktivitas manajemen dalam mengelola perusahaan. Sehingga, banyaknya jumlah managerial ownership tidak dapat mengurangi kemungkinan perusahaan untuk mengalami financial distress.

Variabel institutional ownership tidak berpengaruh signifikan terhadap variabel financial distress. Hasil penelitian ini sesuai dengan hasil penelitian Witiastuti dan Suryandari (2016), Shahwan (2015), Udin dkk. (2017), dan Donker dkk. (2009) yang menemukan hasil bahwa institutional ownership tidak berpengaruh secara signifikan terhadap financial distress. Sedangkan pada penelitian Hanifah dan Purwanto (2013) dan Emrinaldi (2007) ditemukan hasil yang berbeda, yaitu terdapatnya pengaruh negatif dan signifikan variabel institutional ownership terhadap financial distress. Di sisi lain, pada penelitian Balasubramanian dkk. (2019) dan 
Younas dkk. (2021) ditemukan hasil bahwa institutional ownership berpengaruh secara positif dan signifikan terhadap financial distress. Penelitian ini tidak dapat membuktikan adanya pengaruh signifikan antara kedua variabel. Alasan pertama yaitu kecilnya nilai mean atau rata rata variabel institutional ownership yaitu hanya sebesar 0,179571 atau sebesar $17,96 \%$, hal ini menandakan kurangnya kemampuan institutional ownership untuk dapat mempengaruhi aktivitas manajemen perusahaan. Alasan kedua yaitu kemungkinan institutional ownership yang dimiliki perusahaan hanya sebagai formalitas, sehingga fungsi pengawasan tidak benar terlaksanakan.

\section{KESIMPULAN DAN SARAN}

\section{Kesimpulan}

1. Variabel long term debt to equity ratio, retention ratio, return on investment, managerial ownership, dan institutional ownership menunjukkan pengaruh signifikan terhadap financial distress dengan tingkat signifikansi 5\% secara bersama - sama.

2. Variabel long term debt to equity ratio berpengaruh secara positif dan signifikan terhadap financial distress perusahaan dengan tingkat signifikansi $5 \%$.

3. Variabel retention ratio tidak berpengaruh signifikan terhadap financial distress perusahaan dengan tingkat signifikansi $5 \%$.

4. Variabel return on investment berpengaruh secara negatif dan signifikan terhadap financial distress perusahaan dengan tingkat signifikansi $5 \%$.

5. Variabel managerial ownership tidak berpengaruh signifikan terhadap financial distress perusahaan dengan tingkat signifikansi $5 \%$.

6. Variabel institutional ownership tidak berpengaruh signifikan terhadap financial distress perusahaan dengan tingkat signifikansi $5 \%$.

\section{Saran}

1. Bagi peneliti lain, disarankan untuk menggunakan subjek penelitian yang tidak terbatas pada satu sektor perusahaan saja sehingga hasil penelitian lebih dapat menjelaskan masalah penelitian dengan jumlah sampel yang lebih banyak dan beragam.

2. Bagi peneliti lain, disarankan agar menggunakan periode waktu yang lebih lama atau panjang sehingga hasil penelitian dapat mencakup dan menjelaskan topik penelitian dengan periode penelitian yang lebih luas.

3. Bagi peneliti lain, disarankan untuk menambah jumlah variabel independen dengan campuran variabel keuangan dan non-keuangan pada penelitian selanjutnya sehingga dapat meningkatkan signifikansi penelitian.

4. Bagi peneliti lain, disarankan untuk menggunakan kembali variabel corporate governance pada penelitian ini dalam penelitian terhadap financial distress pada perusahaan sektor lain.

5. Bagi perusahaan, disarankan agar dapat bekerja sama dengan akademisi lain dalam memberikan gambaran secara riil faktor penentu apa saja yang memiliki peran penting terhadap financial distress perusahaan.

\section{REFERENSI}

Al-Khatib, H. B. \& Al-Horani, A. (2012). Predicting Financial Distress of Public Companies Listed in Amman Stock Exchange. European Scientific Journal, 8(15).

Balasubramanian, S. A., Radhakrishna G. S., Sridevi P., \& Natarajan, T. (2019). Modeling corporate financial distress using financial and non-financial variables. International Journal of Law and Management, 61(3-4), 457-484. 
Candradewi, M. R. (2019). Pengaruh Good Corporate Governance Mechanism Terhadap Nilai Perusahaan pada Perusahaan di Bursa Efek Indonesia. Jurnal Ekonomi Kuantitatif Terapan, 12(2), 175-185.

Chung, K. H. \& Zhang, H. (2009). Corporate Governance and Institutional Ownership. Journal of Financial and Quantitative Analysis, 46(01), 247-273.

Connelly, B. L., Certo, S. T., Ireland, R. D., \& Reutzel, C. R. (2011). Signaling Theory: A Review and Assessment. Journal of Management, 37(1), 39-67.

Donker, H., Santen, B., \& Zahir, S. (2009). Ownership Structure and The Likelihood of Financial Distress in The Netherlands. Applied Financial Economics, 19, 1687-1696.

Emrinaldi, N. DP. (2007). Analisis Pengaruh Praktek Tata Kelola Perusahaan (Corporate Governance) Terhadap Kesulitan Keuangan Perusahaan (Financial Distress): Suatu Kajian Empiris. Jurnal Bisnis dan Akuntansi, 9(1), 88-108.

Fitri, A. N. (2020, 19 November). PHRI: Kerugian industri pariwisata karena pandemi sudah lebih dari Rp 100 triliun. Kontan.co.id.

Hanifah, O. E. \& Purwanto, A. (2013). Pengaruh Struktur Corporate Governance dan Financial Indicators Terhadap Kondisi Financial Distress. Diponegoro Journal of Accounting, 2(2), $1-15$.

Jensen, M. C. \& Meckling, W. H. (1976). Theory of Firm: Managerial Behavior, Agency Costs and Ownership Structure. Journal of Financial Economics, 3(1976), 305-360.

Kasmir (2009). Pengantar Manajemen Keuangan. Jakarta: Kencana Prenada Media Group.

Kemenparekraf (2019, 15 Juli). Laporan Akuntanbilitas Kinerja Kemenparekraf/Baparekraf. Kementrian Pariwisata dan Ekonomi Kreatif / Badan Pariwisata dan Ekonomi Kreatif Republik Indonesia.

Kristian, M. (2017). Pengaruh Jumlah Dewan Direksi dan Shareholder Equity to Total Asset Ratio Terhadap Financial Distress (Studi Pada Perusahaan Manufaktur yang Terdaftar di BEI Tahun 2012-2015). Jurnal Ekonomi, 22(3), 351-365.

Li, H. X., Wang, Z. J., \& Deng, X. L. (2008). Ownership, Independent Directors, Agency Costs and Financial Distress: Evidence from Chinese Listed Companies. Corporate Governance, 8(5), 622-636.

Lieu, P. T., Lin, C. W., \& Yu, H. F. (2008). Financial Early-Warning Models on Cross-Holding Groups. Industrial Management \& Data Systems, 108(8), 1060-1080.

Murphy, C. B. (2021, 15 May). Guide to Financial Ratios: Retention Ratio. Investopedia.

Nurhidayah \& Rizqiyah, F. (2017). Kinerja Keuangan dalam Memprediksi Financial Distress. Jurnal JIBEKA, 11(1), 42-48.

Platt, H. D. \& Platt, M. B. (2002). Predicting Corporate Financial Distress: Reflections on Choice-Based Sample Bias. Journal of Economics and Finance, 26(2), 184-197.

Ratna, I. \& Marwati (2018). Analisis Faktor - Faktor yang Mempengaruhi Kondisi Financial Distress pada Perusahaan yang Delisting dari Jakarta Islamic Index Tahun 2012-2016. Jurnal Tabarru': Islamic Banking and Finance, 1(1), 51-62.

Sanchiani, D. \& Bernawati, Y. (2018). Pengaruh Kinerja Keuangan dan Pertumbuhan Perusahaan Terhadap Kondisi Financial Distress (Studi pada Perusahaan Tekstil dan Garmen yang Terdaftar di Bursa Efek Indonesia Periode 2012-2016). Jurnal Manajemen Bisnis Indonesia, 5(3), 378-392.

Shahwan, T. M. (2015). The Effects of Corporate Governance on Financial Performance and Financial Distress: Evidence from Egypt. Corporate Governance, 15(5), 641-662.

Simanjuntak, C., Titik, F., \& Aminah, W. (2017). Pengaruh Rasio Keuangan terhadap Financial Distress (Studi pada Perusahaan Transportasi yang Terdaftar di Bursa Efek Indonesia Periode 2011-2015). e-Proceeding of Management, 4(2), 1580-1587. 
Udin, S., Khan, M. A., \& Javid, A. Y. (2017). The Effects of Ownership Structure on Likelihood of Financial Distress: An Empirical Evidence. Corporate Governance, 17(4), 589-612.

Witiastuti, R. S. \& Suryandari, D. (2016). The Influence of Good Corporate Governance Mechanism on the Possibility of Financial Distress. Review of Integrative Business and Economics Research, 5(1), 118-127.

Younas, N., UdDin, S., Awan, T., \& Khan, M. Y. (2021). Corporate Governance and Financial Distress: Asian Emerging Market Perspective. Corporate Governance, 21(4), 702-715.

Yusbardini \& Rashid, R. (2019). Prediksi Financial Distress dengan Pendekatan Altman pada Perusahaan Manufaktur di Indonesia. Jurnal Muara Ilmu Ekonomi dan Bisnis, 3(1), 122129. 